\title{
Traffic Safety along Tourist Routes in Rural Areas
}

\section{Authors: Yiyi Wang, David Veneziano, Sam Russell, and Ahmed Al-Kaisy}

This is a postprint of an article that originally appeared in Transportation Research Record on January 2016. The final version can be found at https://doi.org/10.3141/2568-09.

Wang, Yiyi, David Veneziano, Sam Russell, and Ahmed Al-Kaisy. "Traffic Safety Along Tourist Routes in Rural Areas." Transportation Research Record: Journal of the Transportation Research Board 2568, no. 1 (January 2016): 55-63. doi:10.3141/2568-09. 
Yiyi Wang, Ph.D.

(Corresponding Author)

Assistant Professor

Cobleigh Hall 214

Civil Engineering Department

Montana State University

Bozeman, MT 59715

Phone: 406-994-6051

Fax: 406-994-6105

yiyi.wang@ce.montana.edu

David Veneziano, Ph.D.

Institute for Transportation

Iowa State University

2711 S. Loop Drive, Suite 4700

Ames, IA 50010-8664

Phone: 515-294-5480

Fax: 515-294-0467

dvenez@iastate.edu

Sam Russell, M.S.C.E., M.P.H., P.E.

U.S. National Park Services

1201 Eye St, NW

Washington, DC 20902

Phone: 202-513-7076

Fax: 202-371-6675

samuel_russell@nps.gov

Ahmed Al-Kaisy, Ph.D., P.E.

Professor

Civil Engineering Department

Montana State University

Bozeman, MT 59715

Phone: 406-994-6116

Fax: 406-994-6105

aalkaisy@ce.montana.edu

To submit to the $95^{\text {th }}$ Transportation Research Board Annual Meeting in Washington D.C. for presentation and publication at the Transportation Research Record

Word counts: $5,815+6$ figures/tables $\times 250=7,315$ words 


\begin{abstract}
Little is known about the safety of tourist drivers in the United States. Most domestic studies focused on traffic deaths/injuries of U.S. citizens traveling abroad, citing chief factors such as left-driving, lack of seat belt use, and alcohol consumptions. For states where there are a number of tourism attractions and roadways to reach them, it is of interest to investigate whether traffic safety is an issue for tourist drivers. To that end, this research work investigated the contributing factors for crash severity and crash likelihood of park-visiting drivers in or near three national parks in rural areas. The driver-level data from the Rocky Mountain National Park (ROMO) and the Sequoia and Kings Canyon National Park (SEKI) revealed risk factors for crash severity including age, geometry, seat belt usage, among others. To anticipate crash likelihood of visiting drivers, the second data set offered a more microscopic view at the road level. It contained road geometry, traffic volume, environment, and crash counts aggregated at the segment level along a 57.8-mile tourist route of US Highway 89 (a primary route to the north gate of Yellowstone National Park). Crash risk factors (e.g., geometry and traffic intensity) affected local and nonlocal (tourist) drivers in different ways. Further exploration of crash trends in specific parks would be valuable to understand the overall trends and contributors to crashes in tourism areas and determine the effective improvement measures.
\end{abstract}

Key Words: tourist drivers, traffic safety, crash severity, crash frequency, ordered probit model, spatial multivariate count model, national parks 


\section{INTRODUCTION}

While much progress has occurred in the area of traffic safety, little is known about the safety of tourist drivers in the United States. Most domestic studies focused on traffic deaths/injuries of U.S. citizens traveling abroad, citing chief factors such as driving on the opposite side of the road, lack of seat belt use, alcohol, vehicle conditions, fatigue, roadway and pavement conditions and lighting (1). Within the U.S., the lack of national or local statistics on crashes involving tourist drivers is behind the sparse research and results. For states where there are a number of tourism attractions and roadways to reach them, it is of interest to investigate whether traffic safety is an issue for tourist drivers. Understanding tourist traffic safety is important to the economy too. In Montana for example, tourism brought in $\$ 3.98$ billion in revenue and supported 55,270 jobs in 2013 (2). These tax and job benefits are likely to be offset by the economic and societal costs of traffic crashes involving tourists. While the estimated crash costs vary based on a myriad of factors like severity levels, congestion impacts, and collision manners, traffic crashes in general impose large economic and societal costs (e.g., a fatality costs an average of $\$ 5.83$ million including lifetime and productivity lost, lawsuits, emergency medical service [EMS] costs, etc.) (3).

To better understand tourist driver safety in the U.S., this research study investigated the contributing factors for crash severity and crash likelihood of domestic, park-visiting drivers in or near three national parks. Foreign drivers represented a minute percentage (less than $0.5 \%$ ) of all crash drivers in the three parks studied. Consequently, this study focused on domestic, park visiting drivers, as compared to the literature on tourism traffic safety, which usually targets international drivers. Those domestic, park-visiting drivers were further grouped into local and non-local drivers to capture difference in familiarity with the road and environment. While an exploratory study, the research sheds light on the relevant risk factors and the relationship between visitor drivers and local drivers in traffic crashes. The results can be useful in offering policy considerations for places where visitors/tourists regularly use personal automobiles as a means of transportation.

This paper begins with a Literature Review, followed by a Data Sets section about the data processing details. The descriptive analysis and statistical modeling used are explained next in the Methodology section. Modeling results and interpretation are presented in the Results and Analysis section. The paper concludes with policy and planning implications in the Discussion and Recommendation sections, while limitations and future research are discussed in the Conclusions section.

\section{LITERATURE REVIEW}

Domestic research on tourist traffic safety has been sparse except for a few epidemiologic reports on traffic safety of U.S. citizens traveling overseas (1). A number of international studies have focused on traffic safety in tourism areas. Rosselló and Saenz-de-Miera (4) examined the role of tourism in determining the number of daily crashes in the Balearic Islands of Spain. The 
researchers noted that there existed a void when trying to assess the non-economic impacts of tourism (externalities), specifically aspects such as traffic crashes. The approach considered traditional variables used in safety prediction (e.g., traffic volumes and weather) as well as a daily measure for the amount of tourists at a destination. This measure consisted of observations and estimations of arrivals and departures on the islands via airports and seaports (cruise ships). A negative binomial model was developed to estimate crashes, with the model parameters estimated using the quasi-maximum likelihood method. Using the model, different simulations were run to determine the impact of tourism on crashes. The results indicated that, all other factors being equal, the presence of tourism accounted for 15.8 percent more crashes on the islands than if tourism was not present.

Page and Meyer performed an exploratory analysis of tourism accidents in New Zealand (5). The researchers focused on more than just vehicle crashes in their work, examining insurance/medical claims from highway crashes, sports/recreation injuries, home/lodging injuries and "other" (unspecified) types of accidents. In a review of Accident Rehabilitation and Compensation Insurance Scheme (ACC) data for the year ending June 30, 1994 (the ACC provides a no-fault system of coverage for both New Zealanders and visitors injured as a result of an accident), the researchers found 6.742 insurance claims per 1,000 visitors to New Zealand. Of this, roadway crashes resulted in 3.063 claims per 1,000 visitors. Land Transport Safety Authority (LTSA) data was also examined as part of the work to better understand trends of crashes involving foreign drivers. It was observed that 1.1 percent of all crashes in New Zealand in 1993 involved international drivers. Of the 52 crashes involving foreign drivers, only 16 were determined by police to be caused by the drivers themselves. Based on observations made from the data examined, the researchers concluded that while foreign drivers were not a major factor in the county's overall observed crashes, they do represent a problem in terms of rental car crashes. To this end, potential strategies to address tourist crashes for rental cars included showing videos on common precautions to take, screening of safety messages at car rental agencies, pamphlets and leaflets, prominent signage near airports, tourist resorts, and rental car agencies reminding drivers that New Zealand drives on the left-hand side of the road, and signs on interior vehicle panels to remind drivers of road rules.

Petridou et al. (6) examined the epidemiology of crashes on the island of Crete. Data from a sixmonth period from April to September 1995, involving 730 injury victims from traffic crashes who were admitted to three hospitals of Heraklion District, were examined to determine the patterns, causes, and effects of those crashes. Calculation of odds ratios and statistical documentation was done using the Mantel-Haenszel procedure, which the researchers noted generated results equivalent to those derived from multiple logistic regression. The evaluation found that left-side driving country nationals were at an increased risk for traffic crashes when they drove a rented vehicle $(\mathrm{p}=0.02)$, and were involved 2.5 times more frequently in crashes in which passing or other driving maneuvers required reflexes conditioned on reverse directionality $(p=0.02)(6)$. Alcohol was a primary cause of crashes in a significantly higher proportion of 
foreign nationals $\left(\mathrm{p}<10^{-6}\right)$ and was more common among Eastern Europeans than those from European Union countries $\left(\mathrm{p}<10^{-5}\right)(6)$. The authors concluded that based on these findings, crashes represent a major hazard during pleasure travel and that the victims of those crashes have a distinct epidemiologic profile compared to local residents.

Another research study (7) sought to determine whether crash injuries were disproportionately higher among tourists on the island of Kerkyra (Corfu) in Greece. The researchers examined data from the Emergency Department Injury Surveillance System (EDISS) for all types of accidents, including traffic crashes for 1996 and 1997. Injury comparisons were made between injuries from vehicle crashes versus home and leisure-related injuries. Proportions and chisquare tests were used for the statistical analysis of the data. Examination of the data indicated that traffic crashes represented 40 percent of all injury accidents among foreign tourists. Among foreign tourists, the peak tourism to non-peak tourism ratio for injury accidents was 9.2 for nontraffic accidents, but 15.0 for traffic crashes. The difference between these ratios was statistically significant $(\mathrm{P}=0.008)$, and it appeared that crashes among foreign tourists were disproportionately frequent.

Leviäkangas (8) examined the crash risk of foreign drivers (primarily Russian) in southeast Finland. Specifically, the research focused on differences in crash rates between Russian (foreign) and Finnish (domestic) drivers on two-lane main roads. The results indicated that the crash rates of foreign drivers were much higher than the corresponding rates of Finnish drivers. For example, the crash rate for foreign drivers on one route was 157.7 per 100 million vehicle kilometers versus the Finnish driver rate of 47.6. Winter was observed to be an especially risky season for foreign drivers.

\section{DATA SETS}

Two separate data sets are used to examine the safety issues (i.e., crash likelihood and severity levels) along tourist routes. Both crash data sets report a very small fraction of international drivers (less than $0.5 \%$ ) but a significant number of domestic non-local drivers (those whose driver's license is issued by a state other than the home state of the park or the corridor).

The first data set combines crash records from the Rocky Mountain National Park (ROMO) in Colorado and from the Sequoia and Kings Canyon National Park (SEKI) in California. The data set consists of a total of 1,467 crash parties/drivers involved in 1,184 crashes from 2006 to 2012, along with crash severity levels, road geometry, pavement conditions, and environmental factors (e.g., lighting condition). There were one fatality (which occurred in ROMO in 2007), 24 incapacitating injuries, 74 non-incapacitating injuries, 43 possible injuries, and the remaining 90.3 percent of crash drivers sustained no injury. Given the unbalanced severity level, the five original severity levels are grouped into two levels - injury (fatal, incapacitating injury, and nonincapacitating injury) and non-injury crashes (possible and no injury). The two-level variable (y $=1$ if injury; 0 if no injury) was used as the response variable. 
Explanatory variables are defined by a vector of continuous and indicator variables, including driver characteristics (e.g., age, gender, if local driver, and use of safety belt); speed limits; surface conditions ( 0 = Dry; 1 = Icy/Slushy/Snowy or Debris/Muddy/Wet); lighting $(0=$ Daylight; 1 = Dawn/Dusk; 2 = Dark); and road geometry (Straight and Level; Straight on Grade; Curved and Level; Curved on Grade). The ROMO-SEKI data also provided vehicle makes and models for the occupants (drivers), which were then streamlined into three vehicle types compact, medium-sized (Size.Med.), and full-sized (Size.Larg.) vehicles. Summary statistics are shown in Table 1.

TABLE 1 Summary Statistics of the ROMO-SEKI Crash Data (No. of Obs. =1,092)

\begin{tabular}{|c|c|c|c|c|c|}
\hline & Average & Median & Std. Dev. & Min & Max \\
\hline \multicolumn{6}{|l|}{ Covariates } \\
\hline $\begin{array}{l}\text { If Male }(0=\text { Female; } \\
1=\text { Male })\end{array}$ & 0.783 & 1 & 0.412 & 0 & 1 \\
\hline $\begin{array}{l}\text { Use Restraint }(1= \\
\text { Yes; } 0=\text { No) }\end{array}$ & 0.877 & 1 & 0.328 & 0 & 1 \\
\hline $\begin{array}{l}\text { Lighting } \\
(0=\text { Daylight; } \\
\text { 1=Dawn/Dusk; } \\
\text { 2=Dark })\end{array}$ & 0.287 & 0 & 0.797 & 0 & 2 \\
\hline $\begin{array}{l}\text { Surface }(0=\text { Dry; } \\
1=\text { Otherwise })\end{array}$ & 0.291 & 0 & 0.455 & 0 & 1 \\
\hline If non-local & 0.454 & 0 & 0.498 & 0 & 1 \\
\hline If Straight \& Level & 0.351 & 0 & 0.397 & 0 & 1 \\
\hline If Straight on Grade & 0.212 & 0 & 0.409 & 0 & 1 \\
\hline If Curved \& Level & 0.111 & 0 & 0.314 & 0 & 1 \\
\hline If Curved on Grade & 0.326 & 0 & 0.469 & 0 & 1 \\
\hline If Medium Size & 0.294 & 0 & 0.456 & 0 & 1 \\
\hline If Full Size & 0.619 & 1 & 0.486 & 0 & 1 \\
\hline If Compact Size & 0.087 & 0 & 0.282 & 0 & 1 \\
\hline Age & 44.60 & 45 & 15.86 & 14 & 88 \\
\hline $\begin{array}{l}\text { Speed Limit (mile } \\
\text { per hour) }\end{array}$ & 23.72 & 25 & 12.00 & 0 & 75 \\
\hline \multicolumn{6}{|l|}{ Response Variable } \\
\hline $\begin{array}{l}\text { If injured/killed }(1= \\
\text { Yes; } 0=\mathrm{No})\end{array}$ & 0.061 & 0 & 0.240 & 0 & 1 \\
\hline
\end{tabular}

The ROMO-SEKI crash data were provided by the United States National Park Service (NPS). The two parks are selected based on the relative data quality and a small presence of commute drivers as opposed to park visiting drivers. Both parks are located in this country's western region, and hence the conclusions that result should be interpreted relative to the study area. To generalize the conclusions, the sample should be expanded for a wider coverage of the 66 parks 
that are managed by the NPS. A regional variable may also help to enhance the model as it proxies for region-specific attributes such as precipitation, terrain, and driver behavior, which usually are unavailable from standard crash records. A limitation of the NPS data refers to the disparate sets of attributes provided by each of the 66 parks: for example, some parks record driver-license state (a key variable to control in this study), whereas some do not.

To anticipate crash likelihood of visiting drivers, the second data set offers a more microscopic view at the road level. It contains road geometry, traffic volume, environment, and crash counts aggregated at the segment level along a tourist route of US Highway 89. This route stretches 57.8 miles from Livingston to Gardiner, Montana, and serves as the primary route to the north gate of Yellowstone National Park. Traffic volume or average daily traffic (ADT) was obtained from a dozen temporary and permanent count stations from the Montana Department of Transportation (MDT). Three-years of original crash data were obtained from the Montana Department of Justice (MDJ). Unlike a typical crash form, the original data are stored at the driver or unit level, along with personal information such as driver license state, age, and gender. From 2011 to 2013 inclusive, a total of 163 vehicle crashes were reported along the corridor and involved a total of 214 drivers.

Road geometry attributes were collected from the Road Log Database from MDT. The video logs capture road alignments, surrounding environment, and the pavement underneath from cameras mounted on a survey vehicle. After post-processing, the database converts some of the video information to numeric values, including the vertical grade in percent and the Light Weight Profiler (LWP) International Roughness Index (IRI) at every $1 / 10^{\text {th }}$ second interval. The road video was used by the research staff to define homogenous road segments, resulting in a total of 105 segments with uniform horizontal alignment, rural/urban environment, and crosssection (i.e., number of lanes). Given the absence of land parcel maps, which are useful for calculating built environment variables, the built environment is described by a rural/urban indictor and by the number of signalized and stop-controlled intersections and access points (i.e., driveways or other small access roads that lead to land use on both sides of the roads). Roadside clear zone was recorded into three levels-- poor, fair, and good-depending on the presence of sight obstructions near traffic lanes such as trees, poles, and other built structures.

In order to anticipate the underlying crash rates for local and non-local drivers, their representations in traffic were also collected. Field data collection took place at three intersections for a total of six hours on a weekday in July, 2015. The purpose was to gauge the percentage of local versus non-local vehicles. A fifteen-minute interval was used to aggregate vehicle counts grouped into Montana-licensed (local) vehicles and non-local vehicles. The three count stations were selected from three towns along the route-- Livingston, Emigrant, and Gardiner-- to reflect the changes in the ratios between local and non-local vehicles as the road approaches the park. The Livingston station (the farthest station from the park) produced a local vehicle percentage of $73 \%$, Emigrant $51 \%$, and Gardiner (the closest station to the park) $34 \%$. Table 2 provides summary statistics for the U.S. 89 data set. 
TABLE 2 Summary Statistics of the U.S. 89 Data Set (No. of Obs. $=105$ segments)

\begin{tabular}{|l|r|r|r|r|r|}
\hline & Average & Median & \multicolumn{1}{l|}{$\begin{array}{l}\text { Std. } \\
\text { Dev. }\end{array}$} & \multicolumn{1}{l|}{ Min } & \multicolumn{1}{c|}{ Max } \\
\hline Covariates & & & & & \\
\hline Segment Length (miles) & 0.551 & 0.309 & 0.719 & 0.031 & 5.611 \\
\hline Percent of Local Traffic & 0.491 & 0.511 & 0.164 & 0.344 & 0.733 \\
\hline $\begin{array}{l}\text { If Horizontal Curve (1 Yes; 0= } \\
\text { No) }\end{array}$ & 0.524 & 1.000 & 0.502 & 0.000 & 1.000 \\
\hline LWP IRI & 82.03 & 70.35 & 54.24 & 37.27 & 523.20 \\
\hline No. of Access Points & 3.057 & 1.000 & 5.354 & 0.000 & 30.000 \\
\hline No. of Signalized Intersections & 0.038 & 0.000 & 0.237 & 0.000 & 2.000 \\
\hline No. Stop-Controlled Intersections & 0.452 & 0.000 & 1.594 & 0.000 & 12.000 \\
\hline $\begin{array}{l}\text { Roadside Clear Zone (0 poor; 1 } \\
\text { Fair; 2 = Good) }\end{array}$ & 1.505 & 2.000 & 0.722 & 0.000 & 2.000 \\
\hline If Urban (1 = Yes; 0= No) & 0.105 & 0.000 & 0.308 & 0.000 & 1.000 \\
\hline AADT & 2,904 & 2,097 & 2,623 & 1,643 & 14,613 \\
\hline Response Variables & & & & & \\
\hline No. of Local Crash Drivers & 1.238 & 0.000 & 2.555 & 0.000 & 16.000 \\
\hline No. of Non-Local Crash Drivers & 0.600 & 0.000 & 0.873 & 0.000 & 3.000 \\
\hline
\end{tabular}

\section{METHODOLOGY}

This research focused on safety issues surrounding domestic park-visiting drivers. Since traffic within ROMO and SEKI are predominantly park visitors, the modeling results can be extrapolated to tourist drivers-- both local visitors and non-local visitors.

While a major route for park visitors, the U.S. 89 corridor studied also serves local, non-tourism traffic. Therefore, an assumption was made regarding the definition of tourists and hence a limitation of this study: non-local drivers are considered to represent visitors (mostly park visitors), as opposed to local drivers (some of whom may be park visitors too, but their percentage is unknown). Nevertheless, the interactions between local and non-local drivers relative to traffic crash occurrences, as investigated here, are useful for understanding if the mix has safety implications.

The research mainly answered two questions: what factors contribute to crash rates and severity levels of park visitors; and is there a difference in crash likelihood and severity levels between park visitors/drivers and local drivers? These questions were answered by statistical analyses of traffic crash records from within the two national parks (driver-level data) and from the tourism corridor along U.S. Highway 89 (segment-level data), respectively.

An ordered probit model (OP) was used to estimate the crash severity levels using the ROMOSEKI data set. The mathematical form is shown in Equation 1: 
$y=\left\{\begin{array}{l}0 \text { if } y^{*} \leq 0 \\ 1 \text { if } y^{*}>0\end{array}\right.$ and $y^{*}=x^{\prime} \beta+\epsilon$

where $\mathrm{y}$ is the observed crash outcome ( $\mathrm{y}=1$ if fatal or injured; $\mathrm{y}=0$ otherwise); $y^{*}$ measures the latent risk of fatal/injurious crashes and is expressed as a function of the covariates, or x's (e.g., road, environment, and driver characteristics), their coefficients ( $\beta$ 's), and the error term $(\epsilon)$ that follows a normal distribution. The OP model is a typical tool for analyzing ordered responses, see, for example, Ratanavaraha and Suangka's study on crash severity levels and their respective crash loss values ( 9 ) and Lemp et al.'s extension to account for heteroscedasticity for large truck crash severity levels (10).

A spatial count model was used to simultaneously estimate crash rates of local and non-local drivers while controlling for geometry, environment, and driver attributes. The spatial model was used to mitigate issues associated with missing variables (e.g., lighting, sight distance, and pavement conditions) that show spatial dependence. More mathematical details are referred to these studies: Bansal et al. (11), Chen et al. (12), and Wang and Kockelman (13). The model consists of two stages. The first stage is expressed by a standard Poisson model:

$$
\mathrm{y}_{\mathrm{ik}} \sim \operatorname{Poisson}\left(\lambda_{\mathrm{ik}}\right)
$$

where $\mathrm{y}_{\mathrm{ik}}$ is the number of drivers that crashed at segment $i$; $k$ denotes the type of drivers $(k=1$ if local drivers; $k=2$ if non-local drivers). The mean crash counts, $\lambda_{\mathrm{ik}}$, is coded in the second stage as:

$$
\lambda_{\mathrm{ik}}=\mathrm{E}_{\mathrm{ik}}^{\alpha} \cdot \exp \left(\mathrm{x}_{i}^{\prime} \beta_{\mathrm{k}}+\phi_{\mathrm{ik}}+\mathrm{u}_{\mathrm{i}}\right)
$$

where $E_{\mathrm{ik}}$, the exposure term, is defined as a product of segment length and traffic volume (ADT); the unknown parameter $\alpha$ captures any non-linear relationship between exposure and the mean crash counts of segment $i$. The vector $\mathrm{x}_{\mathrm{i}}$ is a short-hand for the covariates (e.g., traffic volume, a curve indicator, clear zone conditions, number of access points and intersections, and a constant term); $\beta_{\mathrm{k}}$ is a vector of the coefficients specific to driver type $k$. $\phi_{\mathrm{ik}}$ represents a random effect term defined by a multivariate conditional autoregressive distribution (13) to reveal spatial dependence within each driver type and the correlation between the two types of drivers. The remaining unexplained variation is described by the heterogeneity error term, $u_{i}$, unique for each segment.

\section{RESULTS AND ANALYSIS}

The OP model revealed factors that contribute to fatal/injury crashes in ROMO and SEKI, as summarized in Table 3. Eliminating data with missing variables, the model was run over a total of 1,092 crash drivers.

Older tourist drivers were more likely to be injured in a crash than younger drivers, and the use of safety restraints (e.g., seatbelt) can help prevent injuries, as statistically confirmed by the results. Road geometry was coded into four indicator variables: Straight and Level (set as the 
reference level or Road.0), Straight on Grade (Road.1), Curved and Level (Road.2), and Curved on Grade (Road.3). Results show that complex geometry involving either vertical or horizontal curves or both contributed to the likelihood of injury crashes.

Higher speed limit correlated with higher severity level, a finding echoed in research on the relationship between speed and severity $(14,15)$. Vehicle size is a standard factor for crash outcomes, as full-sized vehicles offer more protection to the occupants than smaller vehicles (16). Results suggest that larger vehicle size correlated with lower injury levels (of the occupants), with more reduction benefits from full-sized vehicles than medium-sized vehicles. However, it is possible that large vehicles imposed more devastating impacts and hence increased the severity level of occupants of the other vehicles. But this presumption was not tested by this study due to data constraints.

Among the environmental factors, dark lighting condition (Light.Dark) was found a moderate predictor for fatal/injury crashes, significant under a 90\% confidence level ( $z$ value $=1.83$ ). Roadway surface was cast in a binary way-Surface $=0$ if dry and 1 if snowy, icy, slushy, wet, debris, or muddy, representing all the remaining, compromised surface conditions. Results suggest that adverse surface conditions contributed to lower severity levels, which is consistent with previous findings, see, e.g., (17). Intuitively, drivers tend to slow down under bad weather or surface conditions, and lower speed often prevents serious crash injuries.

The initial model also tested whether non-local visitors/drivers were more likely to be injured in crashes than local drivers. The rationale was that non-local drivers are not as familiar with the roads as local drivers and more prone to errors (perhaps grave ones) due to wayfinding and operating rental vehicles. Based on the OP results, severity levels did not seem to vary between local and non-local tourist drivers, as reflected by a weak significance level, and hence were removed from the final model.

TABLE 3 Outputs of the Ordered Probit Model for Severity Levels Using ROMO-SEKI Data

\begin{tabular}{|c|c|c|c|c|c|c|}
\hline & Coef. & Std. Err. & $\mathbf{z}$ & $\mathbf{P}>|\mathbf{z}|$ & \multicolumn{2}{|c|}{ 95\% Conf. Interval } \\
\hline Age & 0.010 & 0.004 & 2.2 & 0.028 & 0.001 & 0.018 \\
\hline Restraint & -0.585 & 0.177 & -3.32 & 0.001 & -0.931 & -0.239 \\
\hline Light.Dark & 0.379 & 0.207 & 1.83 & 0.067 & -0.027 & 0.785 \\
\hline Surface & -0.351 & 0.165 & -2.13 & 0.034 & -0.675 & -0.027 \\
\hline Size.Med & -0.542 & 0.199 & -2.73 & 0.006 & -0.932 & -0.153 \\
\hline Size.Large & -0.758 & 0.188 & -4.02 & 0.000 & -1.127 & -0.389 \\
\hline Speed.Limit & 0.022 & 0.006 & 3.54 & 0.000 & 0.010 & 0.034 \\
\hline Road.1 & 0.678 & 0.210 & 3.23 & 0.001 & 0.267 & 1.089 \\
\hline Road.2 & 0.656 & 0.251 & 2.61 & 0.009 & 0.164 & 1.149 \\
\hline Road.3 & 0.762 & 0.202 & 3.78 & 0.000 & 0.367 & 1.158 \\
\hline $\begin{array}{l}\text { Cutoff value } \\
\text { (Constant) }\end{array}$ & 1.999 & 0.351 & & & 1.311 & 2.689 \\
\hline
\end{tabular}




\begin{tabular}{|r|r|}
\hline No. of Obs. $=1,092$ \\
\hline LR chi $^{2}(1)=82.54$ \\
\hline Likelihood $=-210.63299$ \\
\hline Pseudo $R^{2}=0.1638$ \\
\hline
\end{tabular}

To evaluate crash risk factors of local/non-local drivers, the study used three-years of crash data from a tourist corridor of U.S. Highway 89-a primary route to the north gate of the Yellowstone National Park. Figure 1 plots the distributions of the two types of drivers against various road and environmental factors.

Curve vs. Straight: Horizontal curves represent 28.6 percent of road centerline miles of the corridor studied. While the majority of crashes occurred along straight segments, a higher percentage of non-local drivers (38\%) were involved in crashes along horizontal curves than local drivers $(23 \%)$.

Number of access points: This variable measured the number of driveways along each homogenous road segment, as a proxy for potential traffic conflicts. Local and non-local drivers responded differently to the number of access points in light of crash propensity. The crash locations of local drivers appeared to cluster on segments that have either too few or too many access points: among the 130 local drivers reported to engage in traffic crashes, 43 percent crashed on segments with less than five access points, and 37 percent crashed on segments with more than 16 access points. By contrast, non-local crash drivers were concentrated on segments with fewer access points: 73 percent of the 63 non-local drivers from the highway patrol records crashed on segments with less than five access points. This difference might indicate disparate driver behavior between local and non-local drivers. The difference could also result from a higher crossing movements by local drivers in order to access adjacent properties.

Roadside clear zone: Coded into three levels (poor; fair; and good), this variable referred to the presence of obstructions (e.g., poles and built structures) in close proximity to traffic lanes such that it affected a driver's ability to traverse back to the roadway. A clear divide is identified between non-local drivers and local drivers in that the former was more likely to crash in impaired clear zones-13 percent of the 63 non-local drivers versus 5 percent of the 130 local drivers.

Rural/Urban: Ninety percent of the studied corridor lies in rural areas, with a small section of the roadway crossing town centers in Livingston, Emigrant, and Gardiner (coded as urban). A higher percentage (32.3\%) of the 130 local drivers were involved in crashes in those urban areas, compared with 12.7 percent of the 63 non-local drivers who crashed in the same urban areas. This can be attributed to a higher exposure of local drivers, as many are residents and patrons of local businesses. 
Intersections: Segments with at least one signalized or stop-controlled intersection bore a higher percentage (33.85\%) of the 130 local driver crashes than the percentage (14.25\%) of the 67 nonlocal driver crashes. This could result from the local drivers representing a greater share of the turning traffic (in order to access land use). As an exploratory research, the study was not able to drill down into the causes of the disparities. This can be achieved perhaps by looking into the behavioral and operational aspects of local/non-local drivers at intersections in future research.

So far, the interactions between local and non-local drivers were not considered. To make that consideration, driver license information available from the crash records during the 2011 to 2013 period were processed to determine if a crash involved only local driver(s) or at least one non-local driver. To control for the different exposures for local and non-local traffic, a field study was conducted at the three locations along the corridor to gauge the ratios between local and non-local traffic by observing the vehicle license plates (Montana or out-of-state). For the corridor under study, the average percentage of local (Montana) license plates was $56.5 \%$ as opposed to non-local (i.e., out-of-state) license plates. As shown in Figure 2, local drivers represented 64 percent of the 136 single-vehicle crashes. The pattern was reversed for multivehicle crashes (a total of 27 over the three years), with non-local drivers representing 64 percent of the multi-vehicle crashes, mostly colliding with a Montana-licensed driver. This distinct pattern between local and non-local drivers is perhaps attributed to speed differences between local and non-local drivers and the tendency of non-local drivers to engage in wayfinding, scenic viewing, and possibly different driving behaviors. 


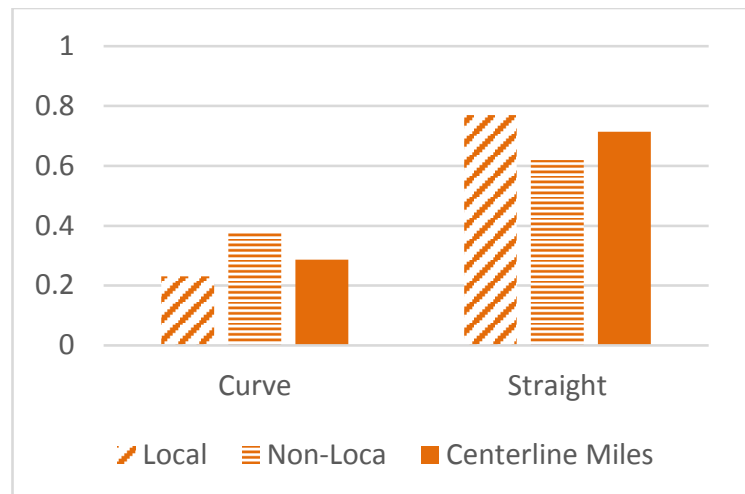

(a) Curves and Straight Segments

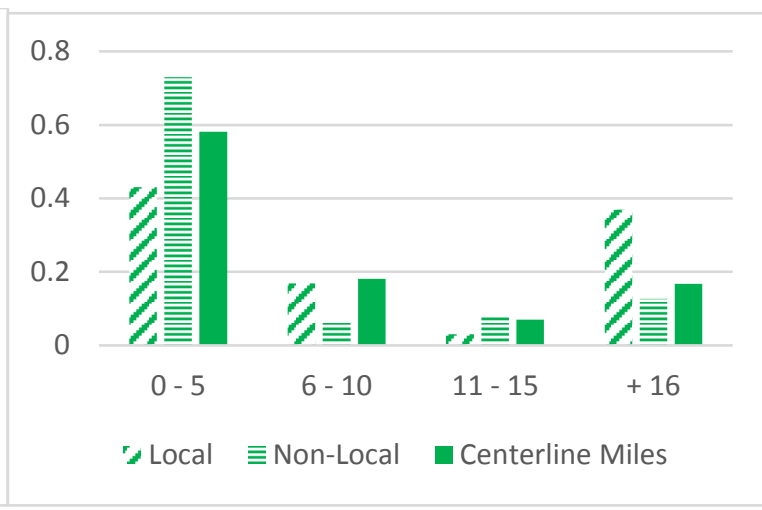

(b) Number of Access Points

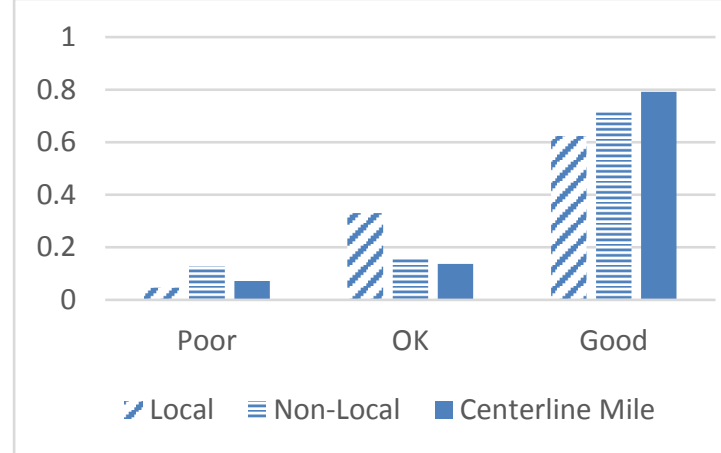

(c) Clear Zone Conditions

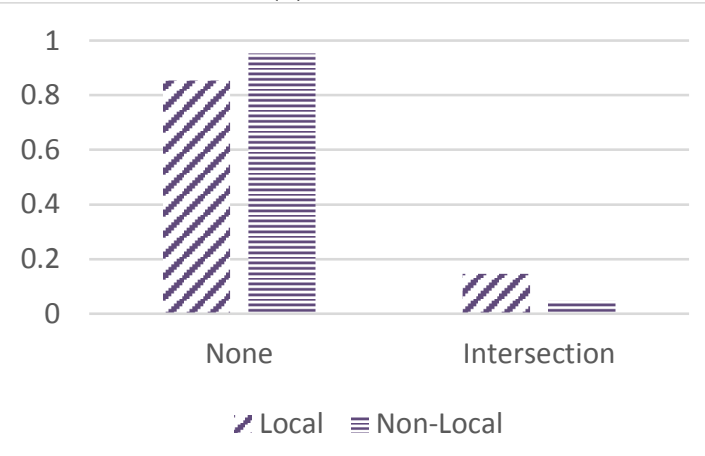

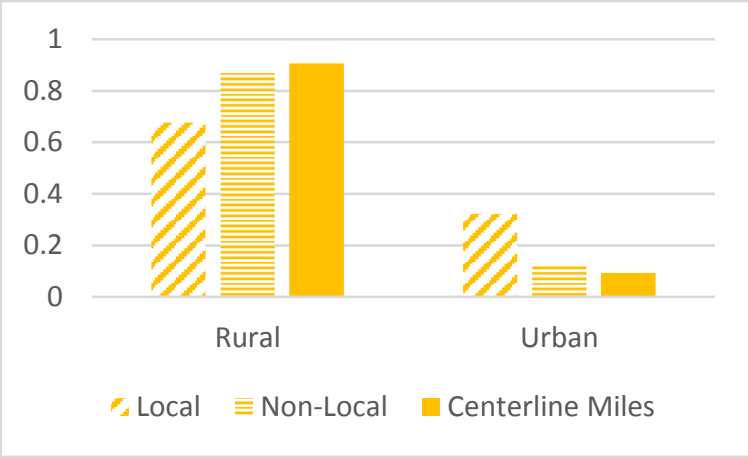

(d) Rural and Urban

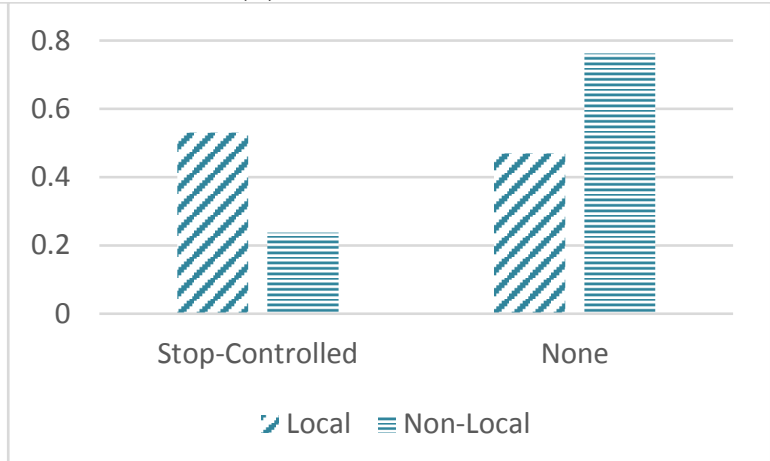

(e) Segments w/ +1 Signalized Intersections (f) Segments w/ +1 Stop-Controlled Intersections

FIGURE 1 Comparisons between Local and Non-Local Drivers Involved in Crashes by Roadway and Environment Features (U.S. 89) 


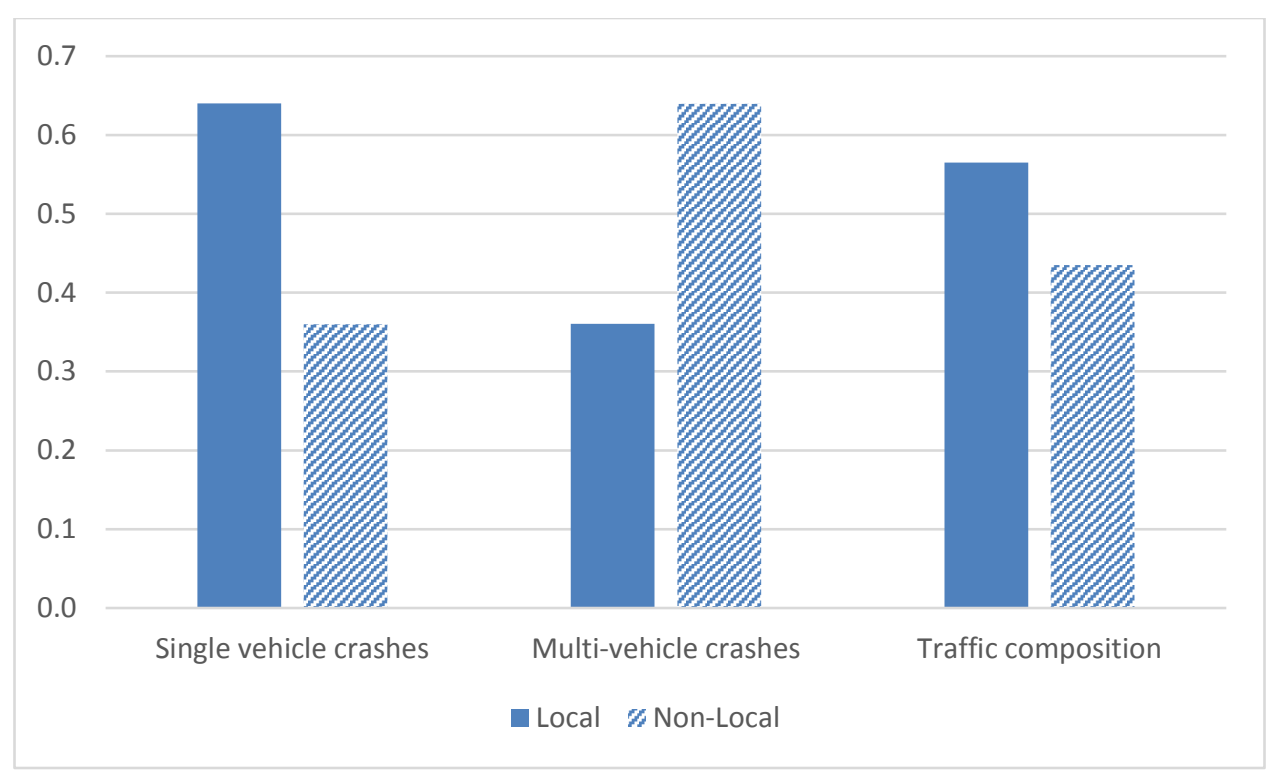

FIGURE 2 Distributions of Local and Non-Local Drivers in Collision Patterns and Traffic (U.S. 89)

A spatial count model was used on the crash data set of U.S. 89 to identify primary risk factors for local and non-local drivers, while controlling for spatial dependence between segments as a result of missing variables. Estimated at the segment level, the model related road geometry, traffic volume, and environmental factors to the number of local and non-local drivers who were involved in traffic crashes during the 2011-2013 period. Table 4 summarizes the model results. The deviance information criterion (DIC) was used to measure the overall goodness-of-fit of the model. The model was run using the Bayesian Markov Chain Monte Carlo (MCMC) method with the statistical packages R and WinBUGS (18). A total of 15,000 samples were drawn for each unknown parameter - the first 3,000 draws were discarded as burn-ins and the remaining 12,000 samples were retained to produce the means and standard deviations for estimating the parameters.

TABLE 4 Results of the Spatial Count Model for Bivariate Response (No. of Observations = 105) Using U.S. 89 Data

\begin{tabular}{|c|c|r|r|r|r|}
\hline & Node & Coefficient & Std. Dev. & \multicolumn{1}{c|}{$\begin{array}{c}\text { Pseudo } \\
\text { t-stats }\end{array}$} & sample \\
\hline & $\begin{array}{c}\text { Non-Local } \\
(2)\end{array}$ & -5.040 & 0.571 & -8.825 & 12,000 \\
\cline { 2 - 6 } & Local (1) & -4.022 & 0.498 & -8.084 & 12,000 \\
\hline \multirow{3}{*}{ Constant } & 2 & 0.460 & 0.300 & 1.533 & 12,000 \\
\cline { 2 - 6 } Curve & 1 & 0.404 & 0.312 & 1.294 & 12,000 \\
\hline $\begin{array}{c}\text { Access } \\
\text { points }\end{array}$ & 2 & 0.112 & 0.035 & 3.241 & 12,000 \\
\hline Volume & 1 & -0.030 & 0.045 & -0.660 & 12,000 \\
\hline
\end{tabular}




\begin{tabular}{|c|c|c|c|c|}
\hline & $-2.19 \mathrm{E}-04$ & $1.01 \mathrm{E}-04$ & -2.164 & 12,000 \\
\hline$\eta_{0}$ & 0.786 & 0.091 & 8.598 & 12,000 \\
\hline$\eta_{1}$ & 0.442 & 0.168 & 2.636 & 12,000 \\
\hline$\rho_{1}$ & 0.638 & 0.111 & 5.762 & 12,000 \\
\hline$\rho_{2}$ & 0.572 & 0.105 & 5.425 & 12,000 \\
\hline$\tau_{\mathrm{v} 1}$ & 0.634 & 0.252 & 2.521 & 12,000 \\
\hline$\tau_{\mathrm{v} 2}$ & 0.844 & 0.237 & 3.565 & 12,000 \\
\hline$\tau_{1}$ & 1.408 & 0.488 & 2.885 & 12,000 \\
\hline$\tau_{2}$ & 1.962 & 0.521 & 3.767 & 12,000 \\
\hline \multirow{4}{*}{$\begin{array}{l}\text { Local } \\
\text { Non-Local } \\
\text { total }\end{array}$} & Dbar & Dhat & $\mathrm{pD}$ & $\mathrm{DIC}$ \\
\hline & 178.248 & 137.038 & 41.21 & 219.457 \\
\hline & 215.523 & 172.356 & 43.167 & 258.689 \\
\hline & 393.771 & 309.395 & 84.376 & 478.147 \\
\hline
\end{tabular}

The bivariate response refers to the counts of local and non-local drivers, analyzed simultaneously. Pseudo t-statistics measure statistical significance; larger absolute values indicate pronounced effects. After controlling for traffic exposure (i.e., the average number of local and non-local vehicles traveling along each segment), traffic volume or AADT was estimated to contribute to non-local driver crash risk but negatively correlated with local-driver crash risk in statistically significant ways. This finding suggests that local drivers cope well with higher traffic conditions, as opposed to non-local drivers whose crash risk increases with higher traffic. The number of access points correlated with higher crash rates for non-local drivers, while its effect on local drivers was insignificant. The model was not able to discern the predictive powers of some variables (e.g., radius), possibly due to the small sample size (No. of Observations $=105$ ).

Thanks to the spatial and bivariate structure, the model also captured spatial dependence among segments and cross-correlations between the two types of drivers. Local drivers tend to cluster along road segments, as do non-local drivers, as reflected by the statistically significant parameters $\rho_{1}$ and $\rho_{2}$. The non-spatial correlation parameter, $\eta_{0}$, measures the relationship between local and non-local driver counts of the same road segment, whereas the parameter, $\eta_{1}$, measures the two types of drivers' correlation that tend to trend in space. Results suggest that road segments that experience a larger number of local-driver crashes also tend to see more nonlocal-driver crashes. This positive correlation is estimated to spillover to neighboring segments, as revealed by the positive coefficient, $\eta_{1}$. Intuitively, it means that a larger number of local drivers having crashed on a segment also predicts a higher crash rate of non-local drivers on the neighboring segments. This is plausible as safety hazards (e.g., poor visibility and adverse surface conditions) on one segment exert similar adverse effects regardless of the driver license state, and these adverse effects are likely to trend in space (e.g., neighboring segments share similar sight distance and surface conditions) It could also indicate adverse safety impacts due to 
the interactions between local and non-local drivers. However, this conjecture should be tested in a more site-specific analysis, which is out of the scope of this study.

\section{DISCUSSION}

Based on the modeling results of the ROMO-SEKI crashes, several observations can be made. First, older drivers were more likely to be injured in crashes than their younger counterparts. Of course, this in part is related to the increased frailty associated with aging, but it also may be related to the general demographics visiting parks and other attractions. Older drivers may comprise a larger proportion of the visitor population to such locations (higher disposable income, more leisure time, etc.) and thus have a higher exposure to crashes.

The finding that more complex geometry contributes to the likelihood of crashes in these locations further underscores the potential relationship that unfamiliar drivers to an area may have with crashes. Complex geometry, combined with the potential for inattentiveness/distraction (viewing scenery, etc.) may combine to make certain locations more dangerous to visitors than they would be in a normal driving environment.

The observation that larger vehicle sizes are tied to lower injury crashes is intuitive in the sense that a bigger vehicle provides more protection for occupants, but it may also underscore a unique aspect of tourism-related destinations and traffic composition. It is possible that tourists are driving larger vehicles to these destinations, such as recreational vehicles, pickup trucks with camper trailers, SUV's and so forth. As a result, when crashes occur, they may be more likely to involve a larger vehicle and potentially reduced injuries. To confirm these conjectures, a more detailed analysis would be needed, and vehicle fleet data should be requested from park entrance records or car rental companies.

Finally, the lighting conditions, specifically darkness, being a moderate predictor of crashes is logical, as unfamiliar drivers to an area are likely to encounter more difficulties in driving on roads they have not been on before. The lower crash severity associated with snowy/wet pavements is also related closely with unfamiliar drivers who are likely to drive more slowly during inclement conditions in an area they are visiting. Additionally, parks often have seasonal visitation trends, and visits during the winter are likely to be lower and result in lower potential for severe or injurious crashes during inclement conditions.

Observations from the U.S. 89 data provide a general view of potential features that may contribute to crashes involving unfamiliar drivers in tourism areas. Curvature was observed to have higher crash involvement for non-local drivers, underscoring that unfamiliarity with a route may present unexpected challenges. Similarly, areas with clear zone issues saw non-local drivers more frequently involved in crashes. Such locations may coincide with unique roadside scenery or other distractions, resulting in increased potential for crash occurrence. Further investigation into such crashes is required before this can be confirmed though. 
The spatial count model run for the U.S. 89 dataset revealed a couple of interesting findings. First, while the finding that higher traffic volumes increased the crash risk for non-local drivers was intuitive, it underscored the challenges that potentially face such drivers in what is an unfamiliar and often complex driving environment. Conversely, the observation that local driver crash risk was not impacted by higher traffic volumes indicates that this driver population has, in part, apparently learned to cope over time with the impacts of tourist traffic. Second, the finding that local and non-local drivers tend to share common crash locations points toward the potential need for roadway improvements or other measures to address crashes at specific sites or in specific ways, particularly for unfamiliar drivers.

\section{RECOMMENDATION}

Based on the findings of this work, several recommendations can be made. First, further research, particularly crash modelling, is necessary to better understand the overall trends and contributors to crashes in tourism areas, particularly sites such as national parks. The research presented here was exploratory in nature and only sought to establish whether non-local drivers were involved to a greater extent in crashes in tourism areas. It appears that non-local drivers are presented with challenges in such locations, and follow-up work should investigate particular aspects of crashes, such as roadway geometry, in greater detail.

A second recommendation is that the development and distribution of educational materials should be considered to prepare drivers for their visit to an area. To an extent, many parks already do this in terms of providing maps. Since these materials exist, it would not be difficult to add tips for driving in the area to these materials, such as being aware that there may be frequent hills, curves etc. on local roads and to exercise caution when driving.

Finally, further exploration of crash trends in specific parks is needed to determine if improvements to signage and wayfinding are needed (e.g., curve delineation with chevrons). While signage installations must be balanced with aesthetic considerations in scenic areas, the benefits to roadway safety need to be heavily considered. Also tied to this is the need for additional research to better understand the nature of crashes in tourist locations in general to determine what additional safety treatments might be considered to address crash patterns.

\section{CONCLUSIONS}

Evidence from this exploratory analysis suggests that national parks and the corridors that lead to them present challenges to non-local drivers who are visiting the area for tourism-related reasons. Issues such as complex geometry may present challenges to unfamiliar drivers, especially older ones. Similarly, reduced lighting conditions and their relationship to crashes are illustrative of the challenges unfamiliar drivers face when in a new area. General observations from a corridor leading to a national park, specifically crashes involving curvature and involvement in crashes where clear zones are poor further illustrate that unfamiliarity with a road and/or area presents challenges to drivers. 
As noted, this work was exploratory, and more detailed analysis is necessary before any definitive conclusions can be drawn. However, it does indicate that approaches to address tourist-related drivers and their unfamiliarity with an area should be considered to proactively address crashes. For example, additional/improved signing may need to be considered. Information targeted toward familiarizing drivers with the roads in the area they will be visiting should also be considered. Such information could be added to park websites and maps to reach visitors before they arrive and while they are planning their visit. Future research could also look into changes in vehicle size operated by park visitors, as vehicle size influences crash propensity, crash severity as well as environmental outcomes.

\section{ACKNOWLEDGEMENTS}

The authors would like to thank Kraig McLeod, Roy Peterson, Mary Padmos, and Michael Deen from MDT and Curt Rissmann from MDJ for providing data. The U.S. National Park Services provided park traffic crash data. Cody West, Josh Taylor, and Shivam Sharda assisted with data collection and entries. The authors would like to thank Andrew Scott for his editorial support.

\section{REFERENCES}

1. The Center for Disease Control and Prevention (CDC) (2015) International Road Safety. URL: http://wwwnc.cdc.gov/travel/page/road-safety. Accessed July 13, 2015

2. Montana Office of Tourism (2014) 2014 Economic Impact Report. URL: http://tourism.mt.gov/Portals/92/shared/docs/pdf/Fast $\% 20$ Facts $\% 20$ \%20Funding\%2001121 5.pdf. Accessed July 13, 2015

3. American Association of State Highway and Transportation Officials (AASHTO). Highway Safety Manual, $1^{\text {st }}$ Edition, ISBN: 978-1-56051-477-0, Washington D.C., 2010

4. Rosselló, J. and O. Saenz-de-Miera. Road Accidents and Tourism: The Case of the Balearic Islands (Spain). Accident Analysis and Prevention, Vol. 43, No. 3, 2011. pp. 675-683.

5. Page, S. and D. Meyer. Tourist Accidents - An Exploratory Analysis. Annals of Tourism Research, Vol. 23, No. 3, 1996. pp. 666-690.

6. Petridou, E., H. Askitopoulou, D. Vourvahakis, Y. Skalkidis and D. Trichopoulos. Epidemiology of Road Traffic Accidents During Pleasure Travelling: The Evidence From the Island of Crete. Accident Analysis and Prevention, Vol. 29, No. 5, 1997. pp. 687-693.

7. Petridou, E., N. Dessypris, A. Skalkidou and D. Trichopoulos. Are Traffic Injuries Disproportionally More Common Among Tourists in Greece? Struggling with Incomplete Data. Accident Analysis and Prevention, Vol. 31, No. 6, 1999. pp. 611-615.

8. Leviäkangas, P. Accident Risk of Foreign Drivers - The Case of Russian Drivers in SouthEastern Finland. Accident Analysis and Prevention, Vol. 30, No. 2, 1998. pp. 245-254.

9. Ratanavaraha V. and Suangka, S. (2014) Impacts of accident severity factors and loss values of crashes on expressways in Thailand. IATSS Research 37(2): 130-136.

10. Lemp, J., Kockelman, K., and Unnikrishnan, A. (2011) Analysis of large truck crash severity using heteroskedastic ordered probit models. Accident Analysis and Prevention, 43(1): 370380 . 
11. Bansal, P., Kockelman, K., and Wang, Y. (2014) Hybrid Electric Vehicle Ownership and Fuel Economy across Texas: Application of Spatial Models. Presented at the 94th Annual Meeting of the Transportation Research Board, Washington D.C., January 2015, and forthcoming in Transportation Research Record.

12. Chen, D., Wang, Y., and Kockelman, K. (2013) Where Are the Electrical Vehicles? A Spatial Model for Vehicle-Choice Count Data. Compendium of the Transportation Research Board's 93rd Annual Meeting, Washington, DC, January 2014. Forthcoming in the Journal of Transport Geography.

13. Wang, Y. and Kockelman, K. (2013) A Poisson-Lognormal Multivariate ConditionalAutoregressive Model for Spatial Analysis of Area-Level Pedestrian Crashes. Accident Analysis \& Prevention 60: 71-84.

14. Kloeden C., McLean A., Moore, V., and Ponte, G. (1997) Traveling speed and the risk of crash involvement. URL:

https://infrastructure.gov.au/roads/safety/publications/1997/pdf/speed risk 1.pdf Accessed July 14,2015

15. Kroyer, H. (2014) Is $30 \mathrm{~km} / \mathrm{h}$ a 'safe' speed? Injury severity of pedestrians struck by a vehicle and the relation to travel speed and age. IATSS Research. In press.

doi:10.1016/j.iatssr.2014.08.001

16. National Highway Traffic Safety Administration (NHTSA) (1997) Relationship of vehicle weight to fatality and injury risk in model year 1985-93 pssenger cars and light trucks. URL: http://www.nhtsa.gov/About+NHTSA/Traffic +Techs/current/Relationship+of+Vehicle+Wei ght+to+Fatality+and+Injury+Risk+in+Model+Year+198593+Passenger + Cars + and + Light + Trucks. Accessed July 13, 2015

17. Lee, J., Nam, B., and Abdel-Aty, M. (2015) Effects of pavement surface conditions on traffic crash severity. Journal of Transportation Engineering 10.1061/(ASCE)TE.1943$5436.0000785,04015020$.

18. Lunn, D.J., Thomas, A., Best, N., and Spiegelhalter, D. (2000) WinBUGS -- a Bayesian modelling framework: concepts, structure, and extensibility. Statistics and Computing, $10: 325-337$ 